\title{
A ciência da saúde coletiva por escrito: contribuição para estudos em saúde bucal coletiva
}

\author{
The science of collective health in writing: \\ contribution to studies in collective oral health
}

Efigênia Ferreira e Ferreira (https://orcid.org/0000-0002-0665-211X) ${ }^{1}$
Raquel Conceição Ferreira (https://orcid.org/0000-0001-8897-9345) ${ }^{1}$
Carlos Botazzo (https://orcid.org/0000-0002-8646-1769) ${ }^{2}$
Viviane Elisângela Gomes (https://orcid.org/0000-0001-9637-1911) ${ }^{1}$
Lorrany Gabriela Rodrigues (https://orcid.org/0000-0002-9531-5392) ${ }^{1}$
Andrea Maria Duarte Vargas (https://orcid.org/0000-0002-4371-9862) ${ }^{1}$
${ }^{1}$ Departamento de Odontologia Social e Preventiva, Universidade Federal de Minas Gerais. Av. Antônio Carlos 6627 , Pampulha. 31270-901 Belo Horizonte MG Brasil. efigeniaf@gmail.com ${ }^{2}$ Faculdade de Saúde Pública, Departamento de Política, Gestão e Saúde,

Universidade de São Paulo. São Paulo SP Brasil.

\begin{abstract}
Celebrating the 25 years of existence of the Journal Ciência \& Saúde Coletiva (CહSC), this paper analyzed 375 documents published between 2000-2019 as an integral part of the editorial of collective oral health. The production analysis aimed to understand how oral health core appears in publications and how it could have contributed to knowledge on the population's health-disease, specific public policies, education, and management of oral health services in the SUS. The process employed bibliometric and documental analysis. We could show the authors' territorial distribution, their extensive collaboration network, and the dimension of citations in publications, including the international plan. The Brazilian states most present in the publications were São Paulo and Minas Gerais, followed by authors from Pernambuco, Rio Grande do Sul, and Santa Catarina. Citations were more frequent in Brazil (85.14\%), followed by the United States (2.31\%), Portugal (1.34\%), and Australia (1.34\%). We concluded that, despite the limitations, the C\&SC showed unequivocally a powerful instrument for the dissemination of scientific production from the perspective of collective oral health, enabling the exchange of information and facilitating the integration between researchers and enabling a path to its consolidation.
\end{abstract}

Key words Periodical, Public Health, Oral Health
Resumo Comemorando os 25 anos da Revista Ciência er Saúde Coletiva (CÆSC), o presente artigo analisou 375 documentos publicados entre 2000-2019 neste periódico, como parte integrante da editoria de saúde bucal coletiva. A análise da produção visou compreender como o núcleo de saúde bucal aparece nas publicações e como poderia ter contribuído com o conhecimento sobre a saúde-doença da população, as politicas públicas específicas, o ensino e a gestão dos serviços de saúde bucal no SUS. O processo privilegiou a análise bibliométrica e a de documentos. Foi possivel explicitar a distribuição institucional dos autores, sua expressiva rede de colaboradores e a dimensão das citações das publicações inclusive no plano internacional. Os estados brasileiros mais presentes nas publicações foram São Paulo e Minas Gerais, seguidos por autores de Pernambuco, Rio Grande do Sul e Santa Catarina. As citações foram mais frequentemente do Brasil (85,14\%), seguido por Estados Unidos (2,31\%), Portugal (1,34\%) e Austrália (1,34\%). Conclui-se que, mesmo com limitações, CひSC se mostrou, inequivocamente, um potente instrumento de divulgação da produção científica na perspectiva da saúde bucal coletiva, possibilitando a divulgação e o intercâmbio de informações, facilitando a integração entre os pesquisadores e possibilitando um caminho da sua consolidação.

Palavras-chave Publicações Periódicas, Saúde Coletiva, Saúde Bucal 


\section{Introdução}

Falar sobre a contribuição e o papel que a divulgação científica da saúde coletiva pode ter ou vem tendo para a pesquisa em saúde bucal coletiva é tarefa que historicamente se impõe. Uma espécie de balanço epistêmico, quando bucaleiros e outros começaram a publicar com regularidade em Ciência \& Saúde Coletiva (C\&SC), desde a edição de seu primeiro número faz mais de duas décadas. Não se poderia, no entanto, falar da C\&SC sem falar da Associação Brasileira de Saúde Coletiva (Abrasco), já bem madura com seus 45 anos. Uma e outra são expressões do vigor com que o campo se movimenta no cenário nacional desde sua emergência no longínquo ano de 1979. Ao fazer este balanço, manifestamos nosso júbilo e nos juntamos ao coletivo nesta mais que merecida comemoração.

Pois saúde coletiva foi naquele momento e continua a ser ainda hoje prática social triplamente configurada: como movimento social ou coletivo de ativistas sanitários; como campo de práticas de atenção à saúde humana; como agenda de investigação ou dispositivo de produção de conhecimento $^{1-3}$. Tais configurações não se encontram livres de contradições nem lacunas epistêmicas. Nem seria o caso de levar em conta tais imprecisões, posto que são delas que se nutrem as boas coisas da vida, as da ciência, inclusive.

Neste artigo buscaremos compreender as relações entre a saúde coletiva e sua expressão particular "bucal", ou, dizendo de outro modo, entre campo e núcleo ${ }^{4}$. De certo modo, buscaremos identificar as determinações e/ou influências ou afetações recíprocas, tomando como referência a publicação de suas ideias e vontades que justificaram nossa presença em C\&SC nas últimas duas décadas. Periódicos e artigos científicos fazem parte da vida diária de pesquisadores. $\mathrm{Na}$ expressão bem-humorada de Eric Hobsbawm, em face da intensa especialização da ciência, cada vez mais os cientistas precisam de publicações "para explicar uns aos outros o que se passa fora de seus respectivos campos" ${ }^{\prime 5}$ (p.506).

Seria o referente saúde bucal coletiva um paradigma no sentido kuhniano? Não obrigatoriamente, se levamos em consideração as interpretações de Moysés e Sheiham ${ }^{6}$. Apoiando-se em Edgard Morin, os autores entendem os problemas teóricos implicados com um conceito que, a despeito de "operacionalmente conveniente", são igualmente "simplificadores ou redutores". Por isso, preferem dizer do paradigma seu caráter de "quase".
Mas a saúde bucal coletiva tem garantido permanência no campo como presença epistêmica. Para "explicar" essa presença, tomaremos em consideração alguns outros referentes, sem o sentido de rigidez conceitual de paradigma. No ponto de partida, precisamos entender quem é o sujeito que fala, ou seja, o que escreve, qual seu referencial teórico-político, qual a sua linguagem, sua inserção no mundo (ou na situação). Assim, entendemos que são cirurgiões-dentistas, mas não apenas, posto que outros sujeitos desde faz muito têm vindo a contribuir no específico reduto do dentário. E depois devemos entender que, em princípio, estes sujeitos adotaram a matriz discursiva da saúde bucal coletiva, cuja expressão incorpora as ciências sociais e humanas, a epidemiologia e a política ${ }^{7}$. Por este motivo, vale interrogar se formariam esses sujeitos uma comunidade epistêmica ou coletivo de pensamento.

No entanto, é muito difícil e às vezes impossível "descrever corretamente a história de um campo do saber”. Um campo ou área é composto de "muitas linhas de desenvolvimento de ideias, que se cruzam e se influenciam mutuamente [....] como se quiséssemos reproduzir, por escrito e com fidelidade [...] uma conversação muito animada, na qual várias pessoas falassem simultaneamente umas com as outras, tentando impor sua voz sobre as demais e na qual houvesse, no entanto, uma ideia comum que vai se cristalizando"8 (p.61).

Essa representação das diferentes opiniões e balizamentos contidos num campo, eloquentemente vista como uma conversação, é bem a expressão do que se poderia dizer de grupos e coletivos alinhados por ideias e conceitos partilhados. Por isso, podemos entender por coletivo de pensamento "a comunidade de pesquisadores que trocam mutuamente ideias ou estabelecem uma interação intelectual e, por esta razão, desenvolvem um estilo de pensamento coletivo". Quiçá venha a ser, pois "um coletivo bem organizado é o portador de um saber que supera em muito a capacidade de qualquer indivíduo"8 (p.89).

$\mathrm{O}$ que eles poderiam refletir como pesquisadores? Como estão contribuindo para o desenvolvimento da ciência e da sociedade? Estas perguntas disparadoras iremos buscar respondê-las, observando alguns parâmetros propostos por Barbosa e Pereira Neto 9 . Nossa análise considerou os seguintes pressupostos:

- [pesquisadores não estão isolados do mundo exterior e são afetados por fatores de fora do mundo científico];

- [atributos de identidade pessoal] são dentistas, formados em diferentes escolas de Odontologia, em diferentes épocas, em diferentes lugares; 
- [como eles compreendem o mundo, isto é,] a prática odontológica, as políticas de saúde, o paciente, a sociedade...;

- [a linguagem que utilizam] as categorias de análise (descritores/unitermos), a construção do pensamento e as conclusões, como isso tudo isso aparece nas publicações;

- [como a produção da saúde bucal coletiva em C\&SC] dialoga com as categorias do social, como aparecem tensões, como o conhecimento influenciou/influencia o ensino, a política de saúde bucal e mesmo a agenda de investigação deste núcleo.

O esforço do artigo visa tornar evidente como a produção teórica da saúde bucal coletiva, ancorada nas Ciências Sociais e Humanas, na Epidemiologia e na Política, se expressa como "coletivo de pensamento" do conjunto dos artigos, publicados na C\&SC. Para tanto, os dados extraídos serão analisados com base em procedimentos de bibliometria e também serão interpretados qualitativamente buscando compreender como os pressupostos acima podem ser recuperados na produção do período. Finalmente, cabe mencionar o que se denomina de translação do conhecimento, aqui visto como o encontro entre o conhecimento científico e o conhecimento fruto da experiência - ou as lacunas entre o conhecido e o utilizado - para considerar possíveis incorporações do conhecimento produzido na gestão dos serviços ou na definição de políticas.

\section{Procedimentos metodológicos}

Os artigos de saúde bucal publicados na C\&SC foram avaliados por dois vieses: um bibliométrico e outro considerando o objeto do estudo publicado. Foi considerada a produção da área no período de 2000 a 2019, disponível na base de dados SciELO, totalizando 375 títulos. Este quantitativo representa o percurso das publicações da saúde bucal coletiva no período, tomando como marco 2000, ano da primeira publicação. Foram considerados todos os tipos de contribuições: artigos originais, de revisão, relatos de casos/experiências, editoriais e cartas ao editor, referidos pelo título e resumo. Para gerar o relatório de citações, foram identificadas na base Web of Science (WoS), seção SciELO Citation Index (Web of Science ${ }^{\circledR}$ ), com exceção do artigo publicado no ano de 2000. Isso aconteceu porque o SciELO Citation Index integrado a WoS disponibiliza os artigos da revista C\&SC a partir do ano 2002. Para a publicação do ano de 2000, o número de citações foi consultado diretamente na base de dados SciELO.

\section{Análise documental}

Todos os artigos identificados na área de saúde bucal foram incluídos nesta etapa do estudo. Foi realizada uma análise documental, que considera em sua essência documentos originais que não tiveram tratamento analítico ${ }^{10}$. Esta técnica de pesquisa qualitativa exige que os dados sejam selecionados, examinados e interpretados a fim de se obter compreensão e significado para o desenvolvimento de conhecimento empírico ${ }^{11}$. $\mathrm{O}$ corpus de análise considerou os artigos que foram organizados pelo ano de publicação e numerados de acordo com a ordem de publicação na revista. Os artigos foram divididos em três blocos, numericamente semelhantes, e três pesquisadoras realizaram, de forma independente, a leitura e extraíram os dados seguindo o roteiro: tema, título, citação, objetivos, tipo de estudo, contribuições para a ciência e para as políticas públicas e os serviços (Sistema Único de Saúde - SUS). Neste estudo, foram considerados para a discussão os temas e as contribuições dos estudos.

Os temas foram definidos previamente com base no núcleo da saúde bucal coletiva que se ancora nas ciências sociais e humanas, a epidemiologia e a política: 1. Ciências socais e saúde; 2. Epidemiologia; 3. Políticas de saúde bucal e avaliação de serviços. O tema 1, incluiu os artigos que discutiram as questões pertinentes ao núcleo da saúde bucal coletiva considerando o referencial teórico das ciências sociais e humanas. No tema 2 estão os estudos que utilizaram a epidemiologia como ferramenta de vigilância e estratégia para a construção de políticas, discutiram o método epidemiológico e criaram modelos teóricos para o estudo das doenças e agravos bucais. No tema 3 foram incluídos os artigos que tratavam de avaliação dos serviços de saúde e aqueles que traziam discussão pertinente para a construção e fortalecimento das políticas públicas, especialmente o SUS.

Os pesquisadores se reuniram durante todo o processo e as dúvidas foram discutidas até o consenso. Ao final do processo de análise, foi construída uma síntese dos artigos considerando as contribuições para a ciência e para o serviço, aglutinadas e analisadas posteriormente. 


\section{Análise bibliométrica}

Considerando a ótica métrica, os seguintes indicadores foram apresentados: 1) frequência absoluta de publicações no período de 2000 a 2019,2 ) frequência absoluta de citações até 2020 , $3)$ número médio de citações de cada publicação por ano; 3 ) fator $\mathrm{H}$ do conjunto de publicações da área de saúde bucal, 4) período até a primeira citação, 5) percentual de publicações que receberam nenhuma citação no período, 6) origem das publicações e citações. Adicionalmente, foi conduzida uma análise da rede de coautorias, tendo por base os autores das publicações e as suas instituições.

A análise das publicações no período considerou a soma do número de documentos publicados em cada ano. O número de citações foi contabilizado considerando os resultados das citações em todas as bases. Essas frequências foram analisadas para o conjunto das publicações e de acordo com a classificação: ciências sociais e humanas, a epidemiologia e as políticas de saúde bucal, incluindo estudos de avaliação de serviços. O número médio de citações de cada publicação foi calculado pela razão entre o número total de citações obtidas por cada publicação dividido pela idade da publicação. A idade foi o resultado da subtração entre o ano de 2020 e o ano da publicação. $\mathrm{O}$ fator $\mathrm{H}$ baseou-se no número de publicações da área de saúde bucal que receberam pelo menos o mesmo número de citações. $\mathrm{O}$ período até a primeira citação foi definido pelo tempo entre o ano da publicação e aquele em que ocorreu a primeira citação. A origem das publicações baseou-se na afiliação ou endereço do primeiro e último autores. As frequências das publicações em cada país e nos estados brasileiros foi representada proporcionalmente por meio de círculos em mapas.

A origem das citações por país foi consolidada com base no relatório de citações até 2020, gerado na Web of Science, referente às publicações de 2002 (ano da primeira publicação da área) a 2019. A distribuição das citações no mundo foi representada por mapas e o total de citações em cada país representado por círculos, cujos diâmetros variam proporcionalmente de acordo com a frequência de citações recebidas. As autocitações não foram excluídas.

$\mathrm{Na}$ mesma base, as seguintes informações sobre as publicações selecionadas foram exportadas para um arquivo ${ }^{\star}$ txt (tab-delimited): tipo de publicação (PT), autores (AU), Editor (PU), ORCID dos autores (OI), Título (TI), Fonte (SO),
Idioma (LA), Tipo de documento (DT), Descritores (DE), Resumo (AB), Endereço do autor (CI), Contagem total de citações (Web of Science Core Collection, BIOSIS Citation Index, Chinese Science Citation Database, Data Citation Index, Russian Science Citation Index, SciELO Citation Index) (Z9), Data da publicação (PD), Ano da publicação (PY), Informações sobre a publicação (volume-VL, número-IS, página inicial-BP, página final-EP, DOI-DI), Área do jornal (SC), Acesso aberto (OA). Para esta análise, foram excluídas as produções com um único autor. O software VOSviewer ${ }^{\circledR}$ foi utilizado para analisar a cooperação científica por meio da avaliação das coautorias, considerando as instituições de origem vinculadas às publicações ${ }^{12}$. O método de similaridade probabilístico, denominado força da associação (Association strength) ${ }^{13}$ foi utilizado para a análise e a definição de clusters e os resultados foram demonstrados em mapas. No mapa, cada círculo representa uma instituição e é identificado pelo seu nome (label). Para evitar sobreposições de nomes, as instituições foram representadas por siglas. O diâmetro do círculo e o tamanho da sigla (label) representa a importância de cada instituição de acordo com a força total do vínculo (link strength). A força do vínculo é definida pelo número de documentos que as instituições possuem em comum. Por exemplo, uma força do vínculo de 2 entre Instituição 1 e Instituição 2 significa autoria comum em duas publicações. Os clusters são identificados por cores diferentes. Linhas entre instituições representam os vínculos entre elas. Quanto maior o número de linhas, maior a força da colaboração científica. A distância entre dois itens na visualização indica, aproximadamente, a relação dos autores e instituições em termos de vínculos de coautoria.

Uma nuvem de palavras foi realizada usando aplicativo Wordle ${ }^{\varpi}$. Os descritores dos artigos selecionados foram agrupados e organizados graficamente de acordo com a sua frequência.

Os dados quantitativos foram organizados e analisados descritivamente usando o programa Microsoft Excel ${ }^{\circledR}$. Os mapas foram criados usando o Infogram (https://infogram.com).

\section{Resultados e discussão}

Contextualizando o período em análise, 2000 a 2019, os primeiros dez anos foram decisivos para a organização da atenção à saúde bucal no Brasil, a partir de sua inserção no Programa (atualmente Estratégia) Saúde da Família, em 2001, por 
meio da Portaria Ministerial no 1.444 , de dezembro de $2000^{14}$.

Em 2003 foi realizada a pesquisa Condições de Saúde Bucal da população brasileira, o SB Brasil-2003, considerado o primeiro diagnóstico aprofundado da situação de saúde bucal da população, com base metodológica bem estruturada e replicável, uma matriz para criação da vigilância epidemiológica em saúde bucal ${ }^{15}$ e, cujos resultados subsidiaram a construção da Política Nacional de Saúde Bucal ${ }^{16}$. Esta política, conhecida como Brasil Sorridente, teve como eixo axial a ampliação da atenção em saúde bucal para a população brasileira.

Neste mesmo ano, ocorreu a $3^{\text {a }}$ Conferência Nacional de Saúde Bucal com o tema, Acesso e qualidade, superando a exclusão social, observada nos resultados do SB Brasil $2003^{17}$.

Em 2006, são implantados os Centros de Especialidades Odontológicas (CEO) e os Laboratórios Regionais de Próteses Dentaria (LRPD), com a introdução do atendimento em nível secundário para algumas especialidades, concretizando mais um passo rumo à integralidade do atendimento $^{18}$.

Encerrando a década, em 2010, foi realizado o SB Brasil 2010, nos moldes da pesquisa de 2003, com a preocupação de aperfeiçoamento do método e estratégias, mas com os mesmos propósitos do SB Brasil 2003, incluindo-se a orientação dos rumos da Política Nacional de Saúde Bucal ${ }^{19}$.

Acompanhando estes feitos, na distribuição anual dos 375 artigos pulicados, observou-se um crescente número de publicações no período. Houve um incremento significante a partir do ano de 2006 (Figura 1a). De 2000 a 2005, 14 documentos foram publicados. À guisa de comparação, somente no ano de 2006 foram publicados 33 documentos, incluindo-se um número temático, Saúde Bucal Coletiva. No editorial deste número, assinado pelos editores convidados, Carlos Botazzo e Paulo Capel Narvai, expressa-se o momento vivido pelo núcleo Saúde Bucal Coletiva, na produção cientifica, condizente com o momento político da década, descrito neste texto: "Se nos últimos anos observou-se expressivo desenvolvimento teórico desta área, registrou-se, também, significativo incremento das práticas, com a reformulação de serviços e o desenvolvimento de novas tecnologias de cuidado"20.

A partir de então, foram publicados anualmente, cerca de 26 documentos, em média com o pico em 2010, quando foram publicados 50 documentos. As publicações sobre políticas de saúde e avaliação de serviços estiveram presen- tes entre os documentos publicados em todo o período avaliado, impulsionando ou impulsionadas pelas mudanças. Nos anos iniciais, houve maior número de publicações na área de Ciências Sociais e Saúde e observou-se um aumento do número de estudos epidemiológicos a partir de 2007 (Figura 1b).

O número total de citações até 2020 foi de 3.039, também crescente no período (Figura 1a). A maioria das publicações recebeu pelo menos uma citação $(\mathrm{n}=316,84,27 \%)$. Os estudos epidemiológicos e aqueles que abordavam políticas públicas foram os mais citados (Figura 1c). A média de citação de cada publicação por ano variou de 0,71 a 6,0. A maior parte das publicações citadas pelo menos uma vez receberam a primeira citação no primeiro $(\mathrm{n}=122,38,61 \%)$ e segundo ( $n=97,30,70 \%)$ anos da publicação. A média de tempo até a primeira citação foi de 2,15 anos (DP $=1,38 ; 1$ a 11). Dos cinquenta e oito documentos ainda não citados $(15,47 \%)$, a maioria $(n=40$; $67,80 \%)$ foi publicado há no máximo dois anos. Dezesseis artigos ainda não citados foram publicados há 5 anos ou mais. $\mathrm{O}$ fator $\mathrm{H}$ foi de 23 . Os vinte e três artigos com pelo menos 23 citações se distribuem nas áreas aqui citadas, contemplado as ciências sociais, a epidemiologia e as políticas públicas e avaliação de serviços.

A C\&SC cumpre seu papel ao acolher artigos científicos de pesquisadores brasileiros, a grande maioria originados dos Programas de Pós-Graduação stricto-sensu. Considerando o período analisado, no núcleo da saúde bucal foram 46,7\% as contribuições na dimensão de Políticas de Saúde Bucal e Avaliação de Serviços, 38,4\% na área de Epidemiologia e 14,9 \% na área de Ciências Sociais.

Esta separação em dimensões exigiu muito esforço dos pesquisadores, uma vez que, em maior ou menor grau, os autores e coautores transitam nos três campos. A intenção foi perceber se a missão definida pela C\&SC, em sua criação, se mantinha fiel por parte dos autores das publicações.

Os estudos trouxeram contribuições para: 1 . transformação dos serviços de saúde, ainda que algumas vezes com abrangência local, contemplando aspectos da atenção primária à saúde, atenção especializada, vigilância em saúde, formação de recursos humanos e discussões relevantes sobre o fortalecimento do SUS, possibilitando reflexões sobre planejamento, necessidades e prioridades nos serviços de saúde bucal; 2. ao conhecimento e reconhecimento do processo de adoecimento da população, com reflexões sobre 
a)

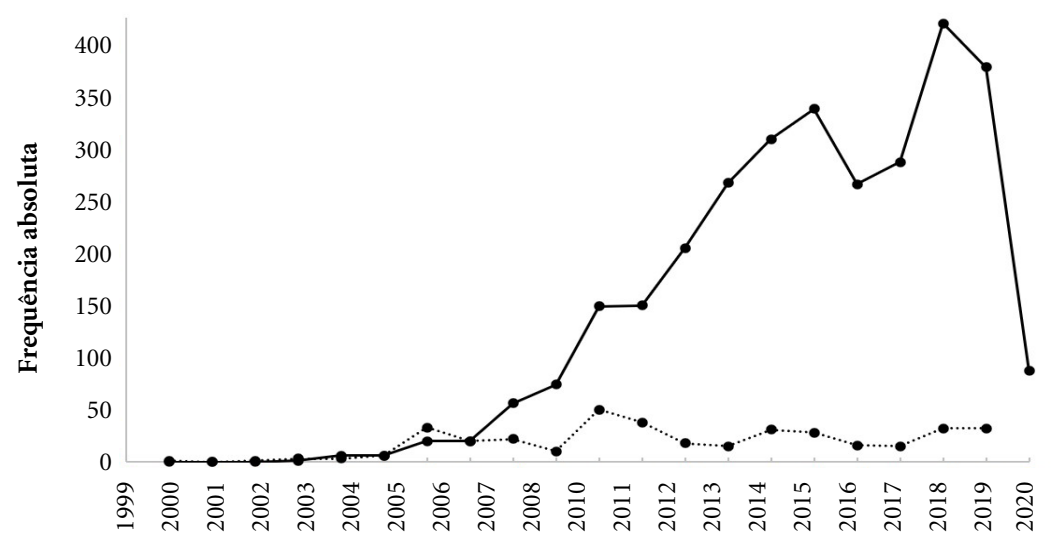

Ano da publicação

•-... Número de artigos por ano de publicação —— Número de citações por ano

b)

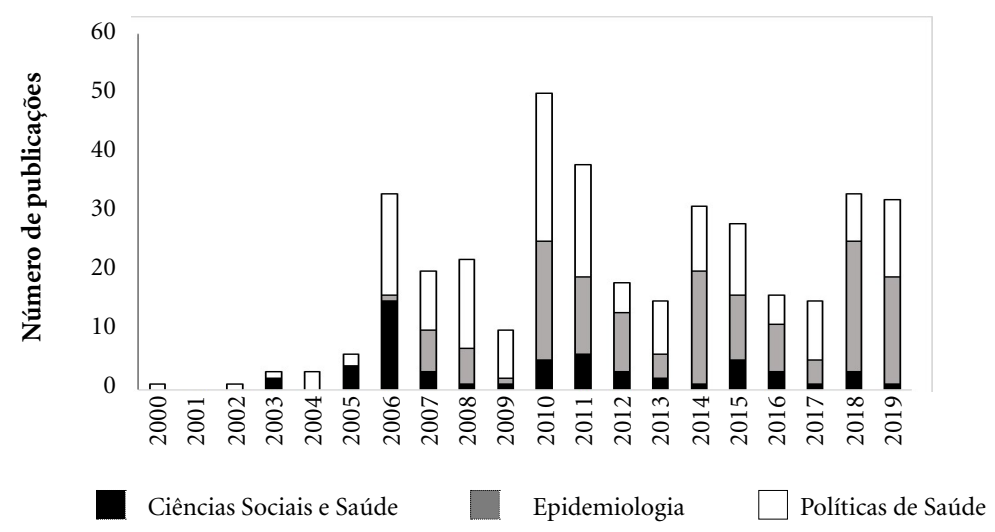

c)

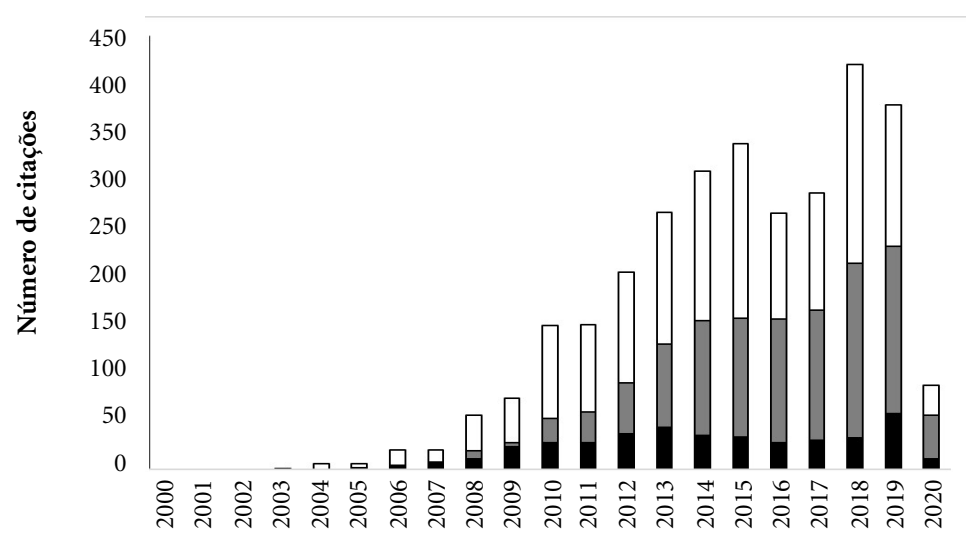

Ciências Sociais e Saúde

Epidemiologia

Políticas de Saúde

Figura 1. Número absoluto de documentos publicados na Revista Ciência \& Saúde Coletiva de 2000 a 2019 e citações obtidas pelas publicações em cada ano, até 2020 considerando o total de publicações $(n=375)$ e a classificação de acordo com os campos da Saúde Coletiva: Ciências Socias e Humanas $(n=56)$, Epidemiologia ( $\mathrm{n}=144)$ e Políticas de Saúde $(\mathrm{n}=175)$. 
a prevalência, incidência e fatores determinantes das doenças e manifestações bucais, iniquidades em saúde e violência interpessoal, contemplando ainda a relação saúde-doença e qualidade de vida; 3. algumas discussões embasadas nas ciências sociais, com foco principalmente na subjetividade em saúde bucal, como ponto crucial a ser considerado em diagnósticos, planejamento, avaliações e políticas públicas, com vistas à efetividade das ações em saúde bucal.

Alguns ensaios teóricos trouxeram reflexões importantes para sedimentação do núcleo da saúde bucal coletiva e fundamentais para o repensar da ciência e prática odontológica, como por exemplo, a discussão do conceito da bucalidade, proposto por Botazzo, em 2006 ${ }^{21}$. Do mesmo modo as reflexões elaboradas sobre o termo saúde bucal coletiva, suas implicações teórico-político-práticas, discutindo a junção de bucal (particularizado) e coletiva (negação da particularização) que, carregando uma aparente contradição, mostra "o esforço desse processo de ruptura, sair do plano do indivíduo e alcançar o plano da coletividade" ${ }^{15}$.

O ensaio teórico sobre a etiologia da cárie, à luz da epistemologia de Ludwick Fleck (18961961) discorreu obre o pensamento odontológico da cárie dentária. Considerando uma construção histórica do conhecimento etiológico, apontando um macro estilo de pensamento, foram identificadas cinco tendências: biologicista, clínico-epidemiológica, clínico-biologicista, biopsicossocial e social ${ }^{22}$.

Os estudos apontaram um comprometimento pontual dos cursos de graduação e pós-graduação com a dimensão ética da formação profissional, bem como avanços em relação à capacitação docente, ao perfil do egresso e ao processo de integração curricular. Por outro lado, indicaram deficiências quanto aos conteúdos relacionados à formação cultural, humanística e política, em relação à orientação didática e aos cenários de ensino-aprendizagem, ao processo avaliativo, Os autores observaram uma incipiente presença da Bioética enquanto disciplina e tema transversal curricular, acompanhada pela escassa formação específica de seus docentes, colaborando nas discussões sobre Projetos Políticos Pedagógicos, frequente a partir de 2000, quando foram estabelecidas as Diretrizes Curriculares Nacionais para os cursos de odontologia, no país ${ }^{23}$.

Não existe ciência que não seja social pois, em termos epistemológicos, "o conhecer representa a atividade mais condicionada socialmente da pessoa, sendo o conhecimento a criação social por excelência" ${ }^{24}$. Dizendo de outro modo, a ciência a serviço do homem é fundamento ético requerido para a produção científica.

Mas a fragmentação do saber científico impregna toda a ciência e não só os estudos aqui considerados. Alano, ao elaborar uma resenha do livro Introdução ao pensamento complexo, de Edgar Morin, ressalta a hiperespecialização do conhecimento, decorrente da fragmentação da realidade, o que resultou em uma cegueira científica, que "destrói os conjuntos e as totalidades, isola todos os objetos daquilo que os envol$\mathrm{ve}{ }^{25}$ (p.142). Observa-se, por exemplo, que parte dos estudos epidemiológicos ainda necessitam transpor a mensuração dos fatores, e considerar o seu vínculo inseparável com a dimensão social ${ }^{24}$. Não existe epidemiologia que não seja social.

As avaliações de políticas públicas e serviços, devem ter como fundamento a solução para os problemas detectados, com vistas à fortificação do SUS e consequentemente, benefícios para a sociedade. Portanto, precisam ser entranhadas da discussão Estado e Sociedade, necessitando cada vez mais da base das ciências sociais.

$\mathrm{Na}$ dimensão das ciências sociais, de maneira geral, observam-se as produções que discutem a subjetividade, por meio da percepção, do auto relato, como tema principal, mais com fundamentos da psicologia (tendência internacional) do que da sociologia, mais usual na produção brasileira. Percebe-se que, algumas vezes se descola da sociedade para a qual deveria servir a ciência produzida.

Essas observações aparecem alinhadas com o estudo conduzido por Celeste e Warmling ${ }^{26}$, quando realçaram diferentes modulações na distribuição temática das publicações em saúde bucal coletiva em periódicos de saúde coletiva e odontologia. Eles concluem que a redução na frequência de algumas temáticas em periódicos de odontologia após 2000 indica que podem estar ocupando outros espaços de debate, mas assinalaram a forte aderência das publicações em saúde bucal coletiva ao arcabouço teórico do campo da Saúde Coletiva ${ }^{26}$.

$\mathrm{Na}$ análise bibliométrica desta série de publicações, considerando a origem dos autores, a maioria apresentou primeira autoria de pesquisadores brasileiros $(\mathrm{n}=371,98,93 \%)$. Quatro documentos possuíam primeiros autores de outros países: Argentina, Colômbia, México e Portugal. Considerando a origem do segundo autor, a distribuição foi semelhante, incluindo-se aqui uma publicação de um autor australiano e outro canadense. Os primeiros e últimos autores foram 
mais frequentemente de São Paulo, seguido por Minas Gerais, Rio Grande do Sul e Santa Catarina (Figura 2).

Este é um resultado natural, para uma revista brasileira, com raízes na saúde coletiva brasileira (ABRASCO), com claros propósitos iniciais ${ }^{26}$, "qualificar o conhecimento do campo na área acadêmica; saúde coletiva, [...] fortalecer a corrente brasileira e latino-americana de concepção de saúde não apenas como objeto dos poderes públicos, mas principalmente, como fruto e construção da sociedade"27(p.337). O núcleo de saúde bucal tem correspondido a estes propósitos.

A Figura 3 representa os países de origem de autores que fizeram citações das publicações da Revista Ciência \& Saúde Coletiva. As citações foram mais frequentemente do Brasil $(85,14 \%)$, seguido por Estados Unidos (2,31\%), Portugal $(1,34 \%)$ e Austrália $(1,34 \%)$.

Embora incipiente, existe uma "rede de citações" da C\&SC, constatando-se que muitos pesquisadores em saúde bucal coletiva no mundo, estão lendo seus artigos e os citando em suas produções, em todos os continentes. Um conhecimento compartilhado com outros locais, que provavelmente apresentam os mesmos desafios a serem enfrentados, e se beneficiam do conhecimento aqui produzido. Mesmo sem se preten-

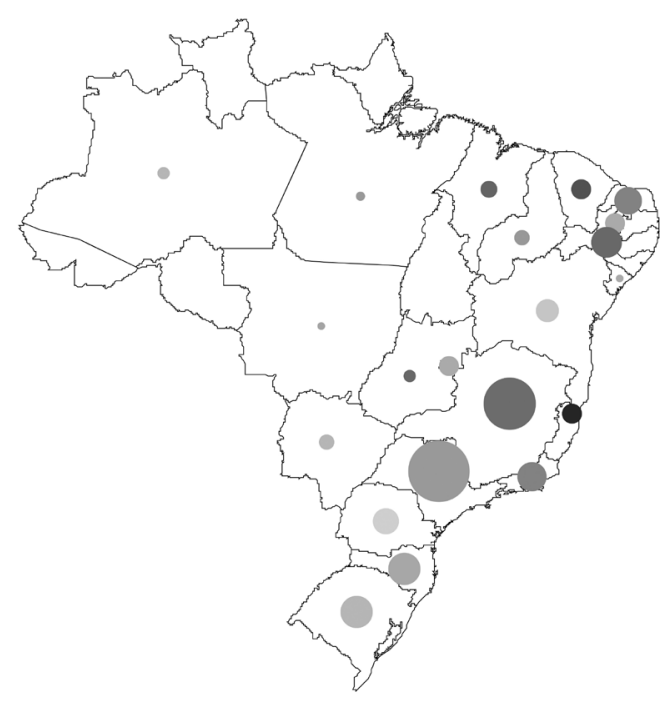

Figura 2. Distribuição das publicações da área de saúde bucal na Revista Ciência \& Saúde Coletiva de acordo com a origem do primeiro autor. der uma análise mais complexa, se atendo ao quantitativo, este é um indicador de qualidade cientifica, característico do desenvolvimento da ciencia ${ }^{28}$.

$\mathrm{Na}$ Figura 4, podemos observar a rede do "coletivo do pensamento", sedimentada e publicada por meio da C\&SC, reunindo cientistas de todas as regiões brasileiras. Foram identificadas 160 instituições nacionais colaboradoras, das quais 140 compartilharam coautorias, ou seja, a configuração de uma rede de produção cientifica abrangendo todo o território brasileiro.

Observa-se no Brasil uma tendência mundial, uma expansão da rede de colaborações com perspectivas de mudanças, como já observado, no eixo central da produção de conhecimento. Causada por uma série de fatores e desdobramentos ainda desconhecidos, essas redes têm contribuído com visões diferenciadas no enfrentamento de desafios e busca de soluções ${ }^{29}$.

Para representar os temas específicos tratados nas produções científicas avaliadas elaborou-se, a partir dos 200 descritores mais frequentes, uma nuvem de palavras (Figura 5). A figura representa toda a análise feita na produção deste artigo. E por aí que transita a "conversa coletiva", essa conversação antes referida, ou essas muitas linhas de desenvolvimento de ideias.

Pelos descritores selecionados pelos autores, os destaques nestes 20 anos foram temas relacionados à epidemiologia, juntamente com alguns subtemas como a carie dentaria, qualidade de vida e perda dentaria, além dos temas idoso e odontologia. Assistência odontológica, saúde pública, atenção primária, Programa Saúde da Família/Saúde da Família, aceso aos serviços de saúde e serviços de saúde bucal, aparecem em segundo plano, no grupo de políticas públicas e avaliação de serviços, observando-se uma frequência maior em avaliações de serviços. Como já observado, temas de ciências sociais são bem mais raros.

\section{Considerações finais}

A escolha da bibliometria e da análise dos documentos publicados nestes 25 anos da revista C\&SC, no núcleo da Saúde Bucal Coletiva, foram adequados para se revelar o coletivo da produção deste núcleo. Foi possível desvelar o caráter criador e inovador da produção intelectual contido nas contribuições, expressa tanto pela abrangência dos objetos abordados quanto pelo uso de metodologias apropriadas aos respectivos 


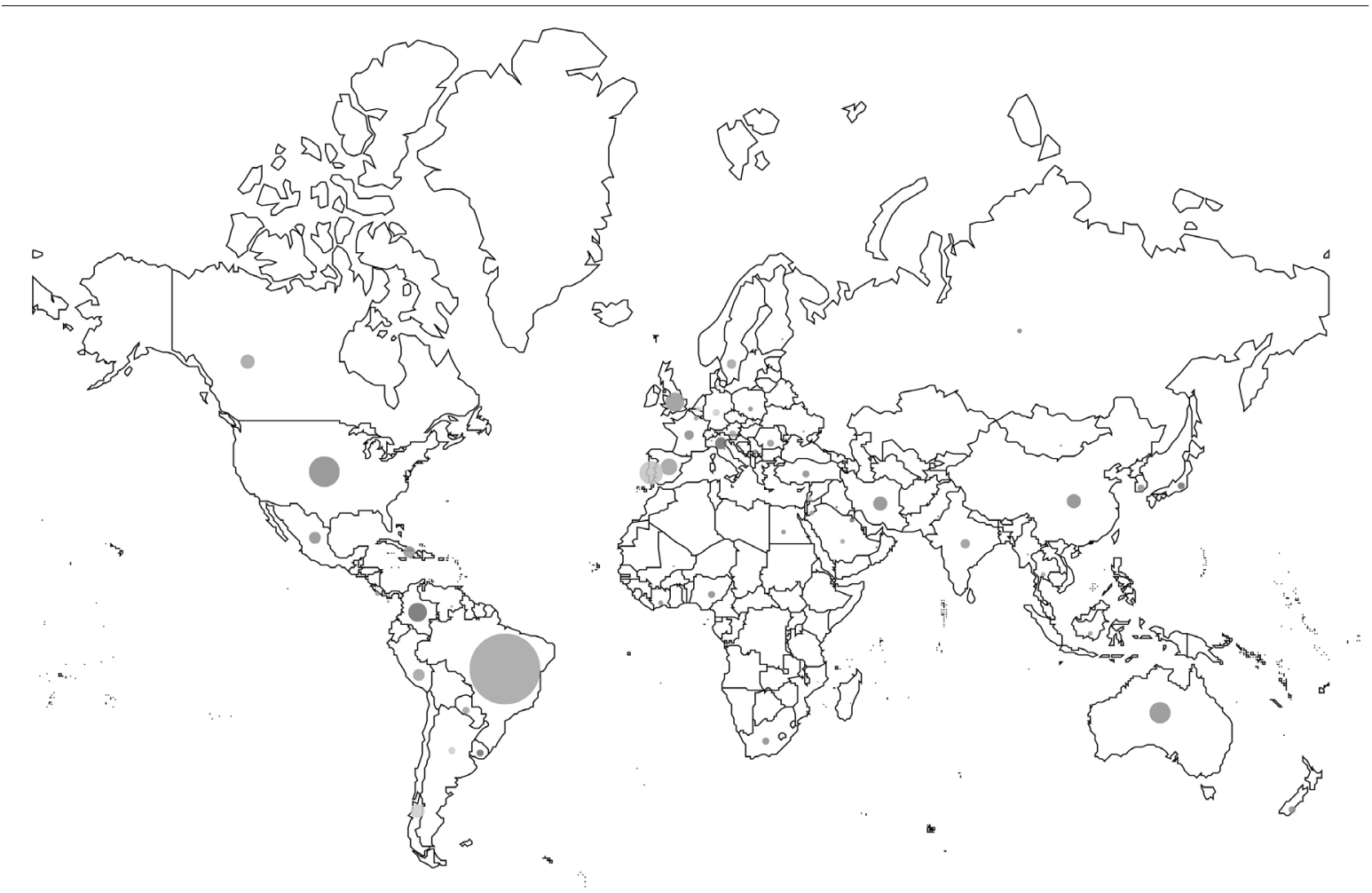

Figura 3. Países de origem das citações das publicações da área de saúde bucal na Revista Ciência \& Saúde Coletiva (citações até maio de 2020).

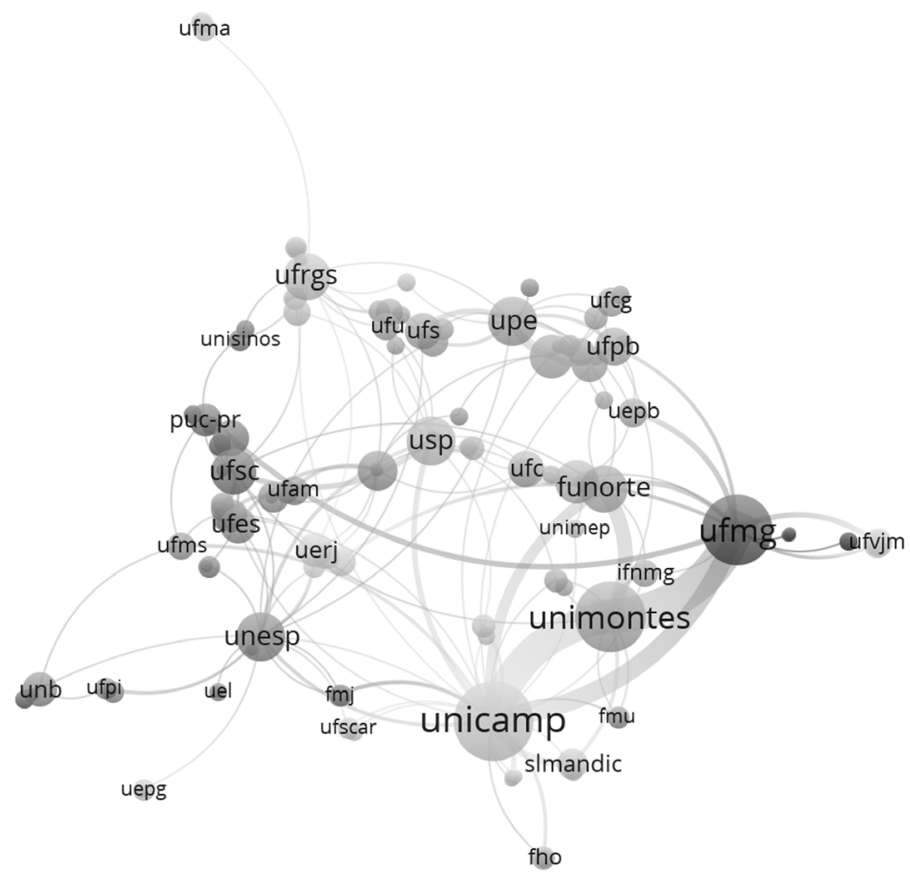

Figura 4. Rede de colaboração entre instituições nas publicações na área de saúde bucal na Revista Ciência \& Saúde Coletiva, de 2000 a 2019. 


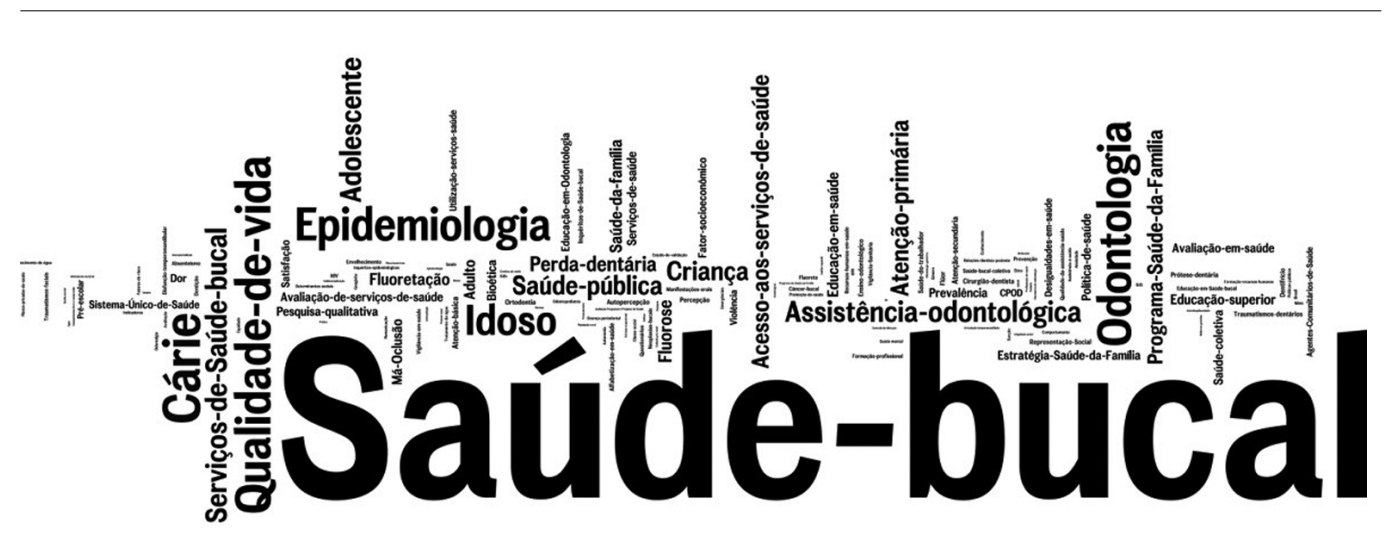

Figura 5. Nuvem de palavras: frequência dos descritores das publicações na área de saúde bucal na Revista Ciência \& Saúde Coletiva, de 2000 a 2019.

recortes. Por outro lado, foi possível observar a distribuição espacial dos autores no Brasil. A despeito de que se achem concentrados em São Paulo e Minas Gerais, não deixa de ser significante o fato de a origem das contribuições cobrir praticamente todo o território nacional, de certo modo formando uma rede de colaboração e de interesse em pesquisa. Observa-se, igualmente, que, mesmo tímida, há formação de uma rede internacional de intercâmbio científico.

Alguns pressupostos não foram confirmados ou confirmados apenas em parte. É o caso do último pressuposto, que aprioristicamente se propôs a perceber diálogos com as categorias do social, e mesmo como o conhecimento produzido poderia ter influenciado o ensino, a política de saúde bucal ou a agenda de investigação deste núcleo. Tais dimensões não puderam ser apreendidas por inteiro. Assim mesmo, aparece ainda que $m$ pequena escala a investigação de recursos humanos, tanto na formação do profissional em graduação e pós-graduação quanto na educação continuada.

Do mesmo modo, observou-se presença de estudos epidemiológicos e avaliativos, e menor ênfase em estudos originados em ciências sociais e humanas. É possível assinalar que a natureza dos estudos epidemiológicos ainda não ultrapassou a barreira da mensuração dos fatores, e considerar o seu vínculo inseparável com a dimensão social. Ou seja, são ainda descritivos e exploratórios em parte dos casos. Por outro lado, os estudos em subjetividade ainda expressam preocupações teórico-políticas mais imediatas, como buscar conhecer representações ou percepções de específicos grupos sociais, em particular gestantes e responsáveis por crianças, pais ou professores.

Apesar desses possíveis limitantes, C\&SC se mostrou, inequivocamente, um potente instrumento de divulgação da produção científica na perspectiva da Saúde Bucal Coletiva, possibilitando a divulgação e o intercâmbio de informações, facilitando a integração entre os pesquisadores e possibilitando um caminho da sua consolidação.

Existe a diversidade de pensamentos e ideias, bem como no modo de produzir o conhecimento, considerando as singularidades de indivíduos e de grupos. Mas é assim que é produzida a ciência, o conhecimento: dialeticamente.

Finalmente, foi possível identificar onde será preciso avançar na produção científica deste núcleo, com vistas ao alcance da meta mais nobre da ciência: a justiça e a equidade, tendo a saúde como direito humano inegociável. 


\section{Colaboradores}

Todos os autores trabalharam na concepção do artigo, na coleta de dados e na estruturação e escrita do manuscrito. RC Ferreira trabalhou na análise estatística. EF Ferreira, AMD Vargas, VE Gomes e C Botazzo trabalharam na análise dos documentos.

\section{Referências}

1. Nunes ED. Cecília Donnangelo: pioneira na construção teórica de um pensamento social em saúde. Cien Saude Colet 2008; 13(3): 909-916.

2. Nunes ED. Saúde coletiva: história de uma idéia e de um conceito. Saúde Soc 1994; 3(2):5-21.

3. Minayo MCS. A produção de conhecimentos na interface entre as ciências sociais e humanas e a saúde coletiva. Saúde Soc 2013; 22 (1):21-31.

4. Campos GWS. Saúde pública e saúde coletiva: campo e núcleo de saberes e práticas. Cien Saúde Colet 2000; 5(2):219-230.

5. Hobsbawm E. A era dos extremos. O breve século XX: 1914-1991. 2a ed. São Paulo: Companhia das Letras; 2010.

6. Moysés SJ, Sheiham A. Saúde bucal coletiva: personagens, autores ou ... Pirandello de novo? In: Kriger L, organizador. Promoção de saúde bucal: paradigma, ciência, humanização. $2^{\text {a }}$ ed. Rio de Janeiro: Artes Médicas; 2003. p. 387-442.

7. Nunes ED. Saúde bucal coletiva: a busca de uma identidade. Cien Saude Colet 2006; 11(1):37-39.

8. Fleck L. La génesis y el desarrollo de un hecho científico. Introducción a la teoria del estilo de pensamiento y del colectivo de pensamiento. Madrid: Alianza Editorial; 1986.

9. Barbosa L, Pereira-Neto A. Ludwik Fleck (1896-1961) e a translação do conhecimento: considerações sobre a genealogia de um conceito. Saúde Debate 2017; 41(n. esp.):317-329.

10. Kripka R, Scheller M, Bonotto DL. Pesquisa Documental: considerações sobre conceitos e características na Pesquisa Qualitativa. Congresso Ibero-Americano de Investigação Qualitativa-CIAIQ 2015; 2:243-247.

11. Bowen GA. Document Analysis as a Qualitative Research Method. Qualitative Res J 2009; 9(2):27-40.

12. Centre for Science and Technology Studies. VOSviewer. Leiden: Leiden University; 2018.

13. van Eck NJ, Waltman L. How to normalize cooccurrence data? An analysis of some well-known similarity measures. J Am Soc Inf Sci Tec 2009; 60(8):1635-1651.

14. Brasil. Ministério da Saúde (MS). Portaria no 1.444 , de 28 de dezembro de 2000. Estabelece incentivo financeiro para a reorganização da atenção à saúde bucal prestada nos municípios por meio do Programa de Saúde da Família. Diário Oficial da União 2000; 29 dez.

15. Roncalli AG. Epidemiologia e saúde bucal coletiva: um caminhar compartilhado. Cien Saude Colet 2006; 11(1):105-114.

16. Brasil. Ministério da Saúde (MS). Secretaria de Atenção à Saúde. Departamento de Atenção Básica. Coordenação Nacional de Saúde Bucal. Diretrizes da Política Nacional de Saúde Bucal. Brasília: MS; 2004.

17. Brasil. Ministério da Saúde (MS). Conselho Nacional de Saúde (CNS). $3^{a}$ Conferência Nacional de Saúde Bucal: acesso e qualidade superando exclusão social. Brasília: MS; 2005.

18. Brasil. Ministério da Saúde (MS). Gabinete do Ministro. Portaria no 599, de 23 de março de 2006. Define a implantação de Especialidades Odontológicas (CEOs) e de Laboratórios Regionais de Próteses Dentárias (LRPDs) e estabelecer critérios, normas e requisitos para seu credenciamento. Diário Oficial da União; 2006. 
19. Roncalli AG. Projeto SB Brasil 2010 - Pesquisa Nacional de Saúde Bucal revela importante redução da cárie dentária no país [editorial]. Cad Saúde Pública 2011; 27(1):4-5.

20. Botazzo C, Narvai PC. Editorial. Cien Saude Colet 2006; 11(1):4.

21. Botazzo C. Sobre a bucalidade: notas para a pesquisa e contribuição ao debate. Cien Saude Colet 2006; 11(1):7-17.

22. Gomes D, Ros MA. A etiologia da cárie no estilo de pensamento da ciência odontológica. Cien Saude Colet 2008; 13(3):1081-1090.

23. Brasil. Conselho Nacional de Educação (CNE). Câmara de Educação Superior (CES). Resolução CNE/ CES 3, de 19 de fevereiro de 2002. Institui Diretrizes Curriculares Nacionais do Curso de Graduação em Odontologia. Diário Oficial da União; 2002.

24. Czeresnia D. Epidemiologia, Ciências Humanas e Sociais e a integração das ciências. Rev Saúde Pública 2008; 42(6):1112-1117.

25. Alano ERC. Introdução ao pensamento complexo. PRACS 2019; 12(3):141-148.

26. Celeste RK, Warmling CM. Produção bibliográfica brasileira da Saúde Bucal Coletiva em periódicos da saúde coletiva e da odontologia. Cien Saude Colet 2014; 19(6):1921-1932.

27. Minayo MCS, Gomes R. Significance and metrics of what is produced by Ciência \& Saúde Coletiva. Cien Saude Colet 2017; 22(2):336-337.

28. Vanz SAS, Caregnato SE. Estudos de citação: uma ferramenta para entender a comunicação científica. Em Questão 2003; 9(2):295-307.

29. Adams J. The rise of research networks. Nature 2012; 490:335-336.

Artigo apresentado em 29/07/2020

Aprovado em 30/07/2020

Versão final apresentada em 01/08/2020 